\title{
Ilustración publicitaria y vida cotidiana en las revistas gráficas: La Esfera (1920-1930)
}

\author{
María ArRoyo CABEllo \\ Universidad Católica San Antonio de Murcia \\ msarroyo@ucam.edu
}

Recibido: 20 de febrero de 2016

Aceptado: 15 de abril de 2016

\section{Resumen}

En el primer tercio del siglo XX España entra en la modernidad debido a la buena coyuntura económica, cultural y social tras la I Guerra Mundial. El objetivo de este artículo es conocer el rol de la publicidad artística en la transformación de la sociedad española durante los años veinte. El estudio de la revista gráfica La Esfera revela que los anuncios ilustrados difundieron la moda, fomentaron el deporte y la vida al aire libre, crearon el hábito de fumar entre las mujeres y tuvieron tal valor educativo que modificó costumbres higiénicas entre la población infantil.

Palabras clave: Publicidad; sociedad; arte; revistas; España.

\section{Advertisement and society in graphic magazine: La Esfera (1920-1930)}

\begin{abstract}
In the first third of the $20^{\text {th }}$ century, Spain entered into modernity thanks to the positive state of its economic, cultural and social domains after the First World War. The objective of this article is to understand the role of artistic advertisements in the transformation of Spanish society that occurred during the decade of the '20s. My study of the illustrated magazine La Esfera has revealed that illustrated advertisements spread fashion, fostered sports and outdoors life, created the habit of smoking among women and had an educational influence that was powerful enough to change hygienic practices among children.
\end{abstract}

Keywords: Advertising; society; art; magazine; Spain.

\section{Referencia normalizada}

Arroyo Cabello, M. (2016). Ilustración publicitaria y vida cotidiana en las revistas gráficas: La Esfera (1920-1930). Historia y Comunicación Social. Vol 21, número 1, páginas 189-202.

Sumario: 1. Introducción. 2. Época dorada de la ilustración publicitaria. 3. Vida cotidiana y anuncios ilustrados. 4. Conclusiones. 5. Referencias bibliográficas. 


\section{Introducción}

En el primer tercio del siglo XX se dan las condiciones para que España entre en la Modernidad: crece la población, las estructuras productivas se renuevan y se producen cambios en la sociedad. En el aspecto económico se crean empresas, bancos y compañías de seguros y se sientan las bases para realizar inversiones y emprender nuevos negocios (García Delgado, 2002). Además, se plantean las primeras reformas en educación, comienza la urbanización de las ciudades y la investigación científica cobra impulso. Mientras tanto las Letras españolas gozan de un periodo de esplendor, que transcurre desde la "generación del 98" a la "generación del 27", y el arte y la música se encuentran en un buen momento creativo. En cuanto a la ilustración publicitaria, atraviesa una etapa espléndida en los años veinte por la coincidencia en el tiempo de magníficos ilustradores y el magisterio de Prat Gaballí, quien no solo introdujo la técnica en la publicidad, sino que también atrajo a este campo a dibujantes de talento como Federico Ribas o Emilio Ferrer (Eguizábal, 2014:116).

Por otra parte, grandes ciudades, como Madrid y Barcelona, viven un gran ambiente cultural que se manifiesta en las tertulias y los numerosos concursos de carteles, cuyo epicentro son los cafés y los círculos artísticos, respectivamente. Por lo demás, en los años de entreguerras surge el cinematógrafo y se inauguran salas de exhibición en las calles céntricas de la capital y de la ciudad condal.

Al mismo tiempo, es una época en la que la vida cotidiana de muchos ciudadanos mejora con el desarrollo de los transportes urbanos, que facilitan el desplazamiento de los barrios alejados al centro de la ciudad; esto beneficia también a sectores como el comercio, los espectáculos, los salones de baile o los cafés. En estos años empiezan a proliferar los grandes almacenes (en 1926 nacen los célebres Almacenes Progreso en Madrid), que suponen una moderna forma de venta, a saber, ofrecer a los consumidores diferentes productos dentro de un mismo establecimiento. Asimismo, aparecen nuevos productos (lavadoras, planchas de vapor, cafeteras, gramófonos, estufas, máquinas fotográficas, etc.), ahora al alcance de una clase media urbana que ha visto aumentar su poder adquisitivo gracias a los logros que reportó a los países neutrales la I Guerra Mundial.

Desgraciadamente, el crecimiento económico no llegaría a toda la población, como bien ha reparado en ello Prat Gaballí (1934:355):

"los años de la Gran Guerra no fueron aprovechados para consolidar marcas en nuestro país y para dejar bien introducidas, con arraigo en el consumo de países extranjeros, muchas otras a las que la ocasión hacía salir de nuestras fronteras".

A pesar de todo, se atisban ciertos cambios en el consumo: por ejemplo, artículos destinados hasta entonces a las clases altas, como sanitarios, cocinas de gas o ascensores, empiezan a formar parte del uso cotidiano de muchas familias de la pequeña y mediana burguesía, al igual que los complementos, es decir, sombreros, guantes y bolsos, que dejan de ser exclusivos de una clase social acomodada (Folguera, 1987: 165). 
Poco a poco surgen nuevos estilos de vida, modos de vestir, hábitos de comportamiento, formas de consumo ${ }^{1}$, deseos y valores, que afectan sobre todo a la mujer hasta entonces prisionera de unos modos de vida que empiezan a cambiar con su acceso a la educación y la incorporación al trabajo. La reciente aparición de nuevas profesiones, como maestras y mecanógrafas, y la llegada a España del deporte, el automóvil o la cosmética abren un panorama insospechado y apetecible a la mujer en los primeros decenios del siglo XX.

Esta transformación de la sociedad española coincide con la que experimenta Europa en el nuevo siglo, la Belle Èpoque, hasta que los efectos de la Gran Depresión americana de 1929 se dejan sentir en los estados europeos. Así pues, España no es ajena a lo que sucede en otros países de su entorno, como tampoco lo es la publicidad, que comienza su profesionalización con la creación de las primeras agencias técnicas, la llegada de grandes anunciantes internacionales y sobre todo la impronta de Pedro Prat Gaballí (Eguizábal, 1998: 453-454). A esto se suma el desarrollo de empresas anunciantes españolas, como la Casa Gal, Floralia, Myrurgia o Artiach, entre otras.

Si bien se han realizado estudios específicos sobre La Esfera (Sánchez Vigil, 2001), Valbuena Álvarez y Salvador Benítez, 2014) y sobre la publicidad artística (Alvarado y De Andrés, 1998 y 1999), (Quintas Froufe, 2008 y 2012), (Lozano Baltolozzi, 1992), (Ortiz Gaitán, 2003), no obstante se trata de enfoques diferentes al que pretendemos dar a este trabajo.

El presente artículo se propone conocer el rol desempeñado por la ilustración comercial en la modernización de la sociedad española en la segunda década del siglo XX, razón por la cual se aborda el tema desde la perspectiva del cambio social poniendo en relación la vida cotidiana con los anuncios ilustrados. En segundo lugar, intenta mostrar las conexiones entre Arte y Publicidad ${ }^{2}$ en una etapa brillante para la publicidad artística.

La metodología utilizada para el trabajo se basa en la observación documental de fuentes hemerográficas, concretamente la revista gráfica La Esfera, desde su primer número del 3 de enero de 1914 hasta el último del 17 de enero de 1931, y la revisión bibliográfica pertinente para los objetivos de esta investigación. Se ha elegido $L a$ Esfera por ser la mejor de su tiempo en su género (Seoane y Sáiz, 1998; Desvois, 1977; Gómez Aparicio, 1974; Pérez Rojas, 1990), por la importancia de la publicidad para la revista ${ }^{3}$ y por el cúmulo de artistas que colaboran en la publicación. Sánchez Vigil (2001) define a La Esfera como un catálogo de obras de arte, en el que se encuentran los mejores ilustradores del primer tercio del siglo XX.

Para realizar el estudio se han seleccionado los anuncios artísticos a página completa, la inmensa mayoría firmados, descartándose los formatos publicitarios inferiores. En este artículo por razones de espacio se han elegido para comentar ocho ilustraciones comerciales representativas, tanto de los cambios que la publicidad propició en la sociedad española de los años veinte como del elenco de dibujantes. 


\section{2. Época dorada de la ilustración publicitaria}

La ilustración comienza a aplicarse a los anuncios en prensa hacia mediados del siglo XIX, si bien se trata de algún alarde tipográfico, orlas y poco más (Pérez Ruiz, 2001:28). Con el nuevo siglo la publicidad artística se asienta ya en las revistas gráficas con pequeñas ilustraciones de corte modernista. Mientras en Estados Unidos se estilaban los anuncios con textos largos y pocas imágenes, en Europa y en España los anuncios se apoyaban en la labor artística para llamar la atención de la marca (Eguizábal, 2002:65).

En la segunda década del siglo XX una nueva generación de artistas irrumpe con anuncios a toda página en el interior $\mathrm{y}$, a veces, en las portadas de las publicaciones gráficas más prestigiosas. De este modo, entre 1925 y 1930 la ilustración se convierte en elemento clave de la publicidad de marcas consolidadas debido a una serie de circunstancias convergentes: la proliferación de concursos artísticos organizados por instituciones y empresas, la confianza de las empresas anunciantes en la publicidad y el apogeo de las revistas gráficas, en cuyas páginas y espacios publicitarios participaron los mejores ilustradores del periodo.

A este respecto dice Prat Gaballí (1934:7):

"el arte ha prestado un concurso precioso a la publicidad abriéndole nuevos caminos de aplicación y así es como el llamado hoy arte comercial se presenta con un florecimiento magnífico, tanto en su producción como en su procedimientos de reproducción".

La celebración de los concursos de carteles procede de finales del siglo XIX en pleno auge del modernismo y vive una nueva época dorada entre 1925 y 1935 (Alvarado y De Andrés, 1998:33). Por lo demás, son una iniciativa de fabricantes e instituciones, que, así, despertaron el espíritu competidor de insignes diseñadores gráficos. Para García Ruescas (2000:171) el decenio 1915-1925 fue un periodo fructífero marcado por la pugna ininterrumpida de tres dibujantes emblemáticos: Federico Ribas, Rafael de Penagos y Salvador Bartolozzi.

Instituciones como el Círculo de Bellas Artes en Madrid y el Círculo Artístico en Barcelona, así como las grandes empresas comerciales Cigarrillos París en 1901 y 1902, chocolates Amatller en 1914 o la Casa Gal en 1916 (Quintas Froufe, 2008) alentaron estos certámenes que tenían una doble finalidad: artística y comercial.

Gracias a los concursos muchos artistas encontraron un trabajo estable, por ejemplo, Federico Ribas se convirtió en el Director de Arte de la agencia Veritas para Gal, Eduardo Jener fue el diseñador de Myrurgia, lo mismo que Penagos de Floralia o Bartolozzi director artístico de la editorial Calleja, realizando periódicamente los anuncios a página completa de las revistas gráficas más importantes del momento, como Blanco y Negro, La Esfera, La Estampa, Nuevo Mundo o Crónica, hasta el punto que la historia del dibujo español del primer tercio de siglo puede seguirse a través de las campañas de Floralia, donde participaron Penagos, Bartolozzi, Téllez, Varela de Seijas, Vázquez Calleja... 
Al principio era habitual que las grandes empresas encargasen los anuncios a famosos escritores e ilustradores, a los segundos mediante los concursos de carteles. Este fue el caso de la Casa Gal, hasta que en 1928 su fundador decidió crear la agencia Veritas previa reestructuración del departamento de publicidad de la empresa, convirtiéndose de esta manera en la primera agencia cautiva española (De Andrés y Alvarado, 1999:54). De su dirección se encargó Pedro Prat Gaballí, que contó con Federico Ribas en la parte artística y con Emiliano Ramírez en la redacción de textos (Altabella, 1950). Prat Gaballí y Ribas mantuvieron una estrecha relación profesional desde abril de 1928 hasta enero de 1936 escribiendo lo que Eguizábal (2002:65) califica como una de las páginas más bellas de la historia de la publicidad española.

En resumen, la publicidad artística debe mucho al sector de la perfumería, que ya a principios de siglo supo transformar la fabricación de productos en industria de marca. El impulsor fue Salvador Echeandía Gal, fundador de la Casa Gal y precursor de la aplicación de las técnicas publicitarias modernas de Prat Gaballí (Arte Comercial, 1950). A él le seguirían otros empresarios con buen olfato comercial y artístico: Alejandro Berenguer y Pascual Flaubel, creadores en 1914 de Floralia y su popular colonia Flores del Campo, Esteve Monegal y Prat, fundador en 1916 de Myrurgia y su célebre perfume Maja, y Joan Parera, promotor en 1912 de perfumería Parera, una marca que tuvo sus mejores años de 1920 a 1930 con la colonia masculina Varón Dandy.

Pero también el auge de las revistas gráficas en torno a la I Guerra Mundial fue decisivo para el desarrollo del arte comercial. La revista se convirtió junto al cartel en el escaparate de exposición y difusión de los productos, sobre todo de belleza y perfumería (Ramos Pérez, 2011:43).

Sin duda fue una etapa floreciente para el periodismo gráfico español, que contó con dos empresas periodísticas notables, a saber, Prensa Española (1909), editora de ABC y la revista Blanco y Negro y Prensa Gráfica (1914), editora de varias publicaciones (Nuevo Mundo, Alrededor del Mundo, Por esos Mundos y Mundo Gráfico), a las que se sumó el 3 de enero de 1914 La Esfera. De entre todas las revistas de Prensa Gráfica, La Esfera era la publicación estrella no sólo por su esmerada impresión sino sobre todo por las excelentes colaboraciones literarias y artísticas de los mejores escritores y dibujantes del momento. Además, fue uno de los más importantes medios de difusión del Art Déco (Pérez Rojas, 1990).

En 1924 Prensa Gráfica perdió la propiedad de sus publicaciones, que fueron adquiridas por la agencia Publicitas de Barcelona, si bien Prensa Gráfica conservaría los derechos sobre estas revistas en régimen de arrendamiento hasta 1932, en que pasaron a depender exclusivamente de Publicitas (Desvois, 1977: 74).

Y sobre todo se debe a los dibujantes publicitarios, cuyo arte e ingenio imprimieron sello propio a la publicidad española, que en ese momento estaba incorporando la técnica norteamericana, importada por Prat Gaballí. Así pues, en la segunda década del siglo XX un grupo de jóvenes dibujantes renovaron el diseño gráfico y la ilustración publicitaria en España. Sus anuncios firmados infundían calidad a la marca y, al 
mismo tiempo, eran eficaces desde el punto de vista publicitario porque aumentaban las ventas.

Por tanto, podemos decir que esta vez la publicidad influyó en el arte, pues aunque los artistas eran conocidos y contaban con experiencia, los concursos de carteles los catapultaron a la fama; la publicidad les proporcionó un trabajo fijo en las agencias, departamento publicitario del anunciante, prensa, publicaciones gráficas y editoriales. Su obra publicitaria ha quedado inmortalizada en infinidad de carteles y en las páginas de las revistas ilustradas, adquiriendo la misma consideración que el resto de su producción gráfica.

\section{Vida cotidiana y anuncios ilustrados}

El contexto en el que aparece La Esfera es el apogeo de las revistas gráficas, algunas de gran calidad literaria como Germinal, España o La Revista de Occidente. Pero a diferencia de estas publicaciones minoritarias, La Esfera junto a Blanco y Negro se dirigen a un público más heterogéneo y les cabe el mérito de acercar la cultura a ambientes selectos pero menos cultivados. La Esfera, fundada por el periodista y también dibujante Francisco Verdugo Landi, que sería su director toda su existencia, salió a la calle el 3 de enero de 1914 como semanario gráfico hasta su desaparición el 17 de enero de 1931. La Esfera fue una revista de calidad, de precio alto -más del doble que el resto del mercado- y de mayor tamaño (formato magazine), de entre 30 y 35 páginas, que en ocasiones especiales podía llegar a 70 o más ${ }^{4}$, editada en papel couché y con una tirada de 45.000 ejemplares (Desvois, 1977: 156-157). Desde el principio destacó por

"la variedad y calidad de sus colaboraciones, por la audacia de sus estampaciones a color y por la riqueza y multiplicidad de sus grabados -un alarde de buen gusto y de perfección técnica que la equipararon a las mejores publicaciones extranjeras de su clase" (Gómez Aparicio, 1974:546).

El principal reclamo de la publicación fueron las portadas y los anuncios ilustrados a color con cuidadas obras artísticas y fotografías. Estaba dirigida a un público perteneciente a la alta burguesía y por medio de las imágenes y de la publicidad insertada en sus páginas fue penetrando en España la moda y los nuevos modelos de vida que imperaban en Europa. Novedades que hicieron mella sobre todo en la mujer, quien se convirtió en el principal objetivo de las empresas anunciadoras y en el target preferido por la publicidad. La mayoría de los anuncios ilustrados de La Esfera estaban pensados para un consumo reservado a personas pudientes, cosmopolitas, seguidores de la moda y de todo cuanto venía de fuera.

Tal es el caso de los anuncios referidos al sector del automóvil de las marcas de lujo Lincoln y Ford, recién llegadas a España en 1920. Fijémonos en la ilustración comercial (figura 1) de 1925 del madrileño Rafael de Penagos (1889-1954) para Lincoln, en la que en primer plano aparece una mujer distinguida asomada a la venta- 
nilla del coche, mientras que el segundo plano es para el coche, cuyo chofer pasea a la dama por un boulevard. El texto, integrado en la ilustración, asocia la elegancia de la mujer con la del vehículo. Y esta otra (figura 2) de 1930 del dibujante gallego Federico Ribas (1890-1952) para Ford. También aquí en primer plano destaca una joven vestida a la última moda y al fondo el automóvil con el chofer. El texto, integrado en el dibujo, define el coche Ford como el ideal de toda mujer elegante y práctica. Con este tipo de ilustraciones tanto Penagos como Ribas contribuyen a la difusión en España de la moda y la alta costura europea: vestidos escotados, labios rojos, tejidos a cuadros, abrigos con esclavina, sombrero cloche o zapatos de tacón alto.

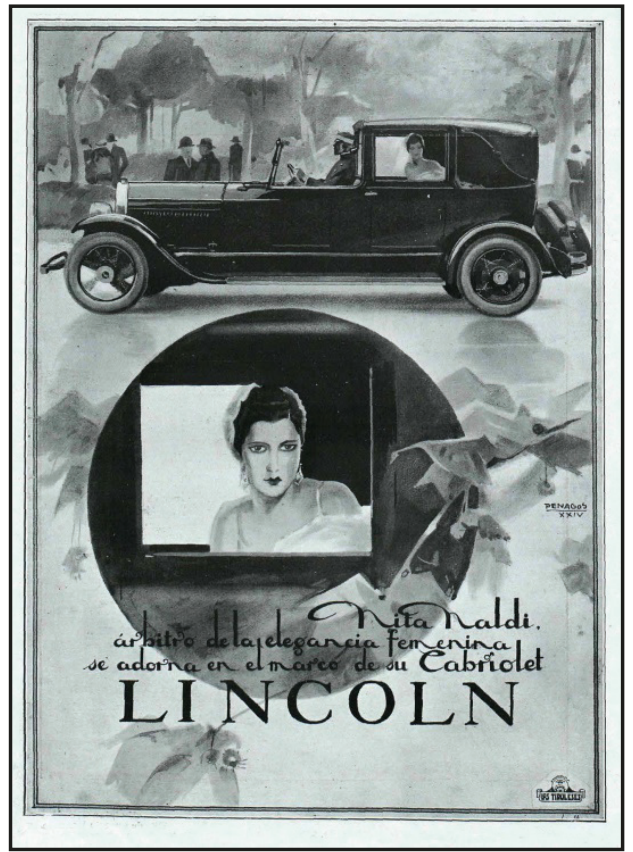

Figura 1: La Esfera, 31/01/1925

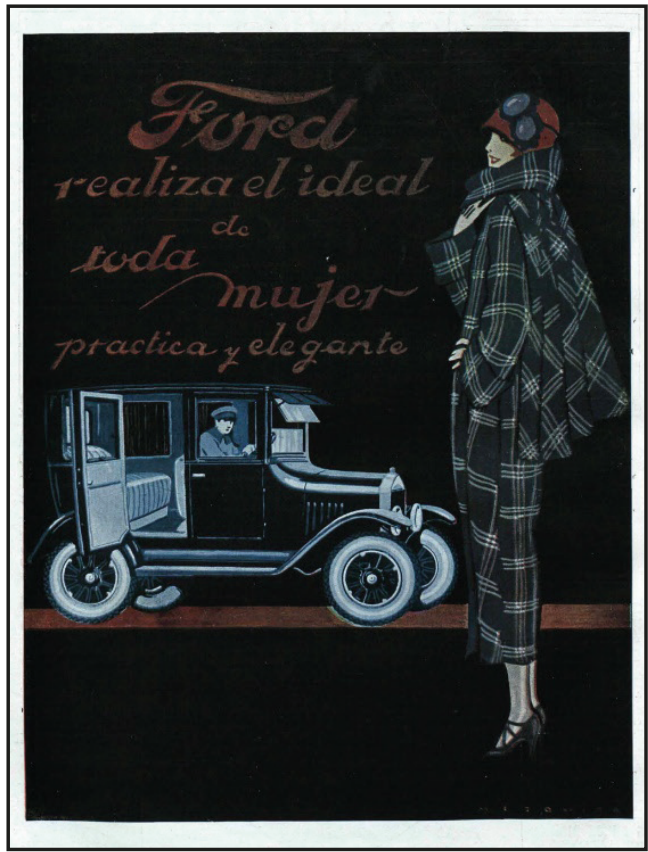

Figura 2: La Esfera, 28/02/1925

Ahora bien, mientras la ilustración de Penagos apela a un valor de consumo restringido (la elegancia), la de Ribas añade otro valor de consumo masivo: la practicidad. Esta dualidad de los modelos de consumo se debe a que durante los años veinte cohabitan en España los dos tipos de consumo: el de elite y un incipiente consumo fondista, entonces vigente en Estados Unidos, que no conseguirá normalizarse en España hasta los años sesenta (Martín, 2002:47).

La dictadura de Primo de Rivera favoreció el consumo, ya que mejoraron las obras públicas, se construyeron carreteras y, en consecuencia, aumentó el parque automovilístico en ciudades como Madrid. Además, entre 1920 y 1930 se instalaron en España otras marcas, como Citroen, Fiat, Renault o Peugeot, más asequibles para un público 
de clase media. En esta línea se enmarca el dibujo (figura 3) de 1927 del vallisoletano José Loygorri (1884-1970?) para Renault, en el que nos muestra en primer plano a una pareja en la nieve y al fondo el automóvil, pero sin chofer. El texto que acompaña a la ilustración vincula el automóvil a valores de consumo masivo como la utilidad y la potencia. Loygorri consigue plasmar los cambios que se están produciendo con tres ideas gráficas: el deporte, la moda y el uso del vehiculo.

Progresivamente el consumo de automóviles va llegando a profesionales liberales y hombres de negocios, que de este modo disponen de un medio de transporte rápido, económico y seguro, valores a los que se asocia ahora el coche, tal y como decía un anuncio de Fiat de 1930. Y surgen nuevos productos derivados de la industria automovilística, como son los neumáticos Dunlop y Continental, en cuyos anuncios figura ya el argumento de compra, el producto, el precio, la marca, el lugar de venta

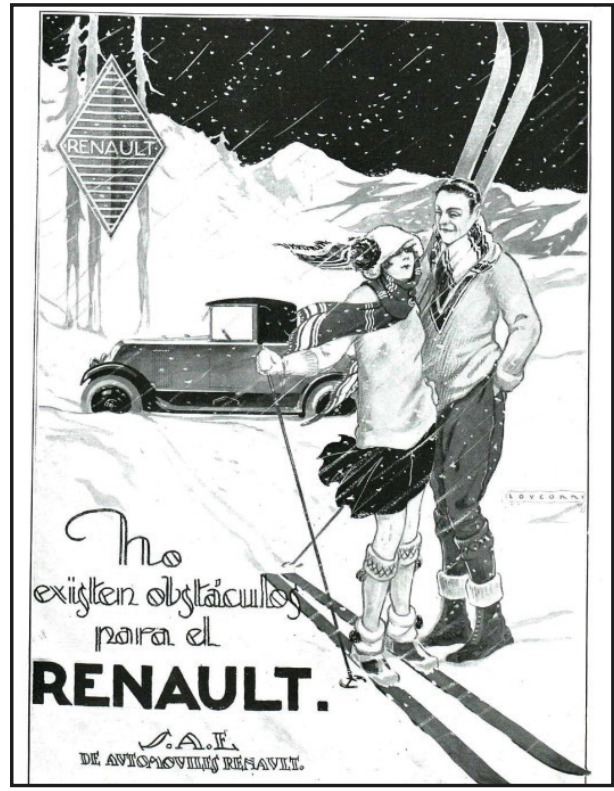

Figura 3: La Esfera, 1/01/1927

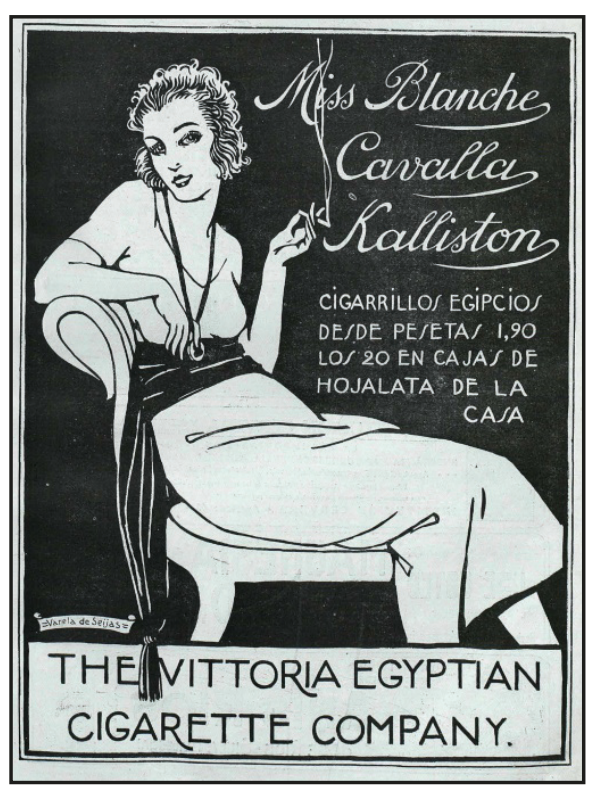

Figura 4: La Esfera, 15/10/1921

Otro sector que influyó en la transformación de la sociedad española fue el tabaco, que creó el hábito de fumar entre las mujeres. De 1901 data el famoso cartel que Ramón Casas realizó para los Cigarrillos París; más tarde, en la década de 1920 serán los anuncios de los denominados Cigarrillos Egipcios los que ocupen los espacios publicitarios de las revistas gráficas. La Esfera publicó varias versiones realizadas por dibujantes del momento: Varela de Seijas, Stimber, Povo, entre otros, donde siempre la protagonista es una mujer con un cigarrillo en la mano. Tomemos como ejemplo el dibujo (figura 4) de 1922 del gaditano, insigne representante del modernismo 
madrileño, Enrique Varela de Seijas (1868-1955), en el que una joven enfundada en un escotado vestido reposa sobre un diván mientras consume un cigarrillo. Aquí el artista asocia el estilo chic de la chica con fumar, algo completamente novedoso para la española de la época.

Pero con toda seguridad fue el sector de la perfumería el que absorbió la mayor parte de la publicidad artística de las revistas gráficas. Conviene recordar que la cosmética era de las pocas industrias españolas bien organizadas en cuanto a producción de bienes de consumo y publicidad. Decía Prat Gaballí (1934:357) que treinta años atrás no existía en España la industria perfumera y también "que la evolución de la industria nacional de la perfumería va unida a la historia de la publicidad metódica, estudiada, artística y psicológica".

En efecto, en los años veinte Gal, Myrurgia y Floralia dominaban el mercado nacional y comenzaban su expansión internacional. Esta pujanza del sector se había logrado gracias a la publicidad.

La Esfera publicó en portada, en 1916, los carteles presentados al concurso de Gal para Heno de Pravia, previa adquisición de los derechos de publicación (Alvarado y De Andrés, 1998:35), y a lo largo de 1917 irían apareciendo la serie de trajes regionales que Federico Ribas hizo también para Heno de Pravia. Pero fueron muchas más las portadas que realizó Ribas para los productos de $\mathrm{Gal}^{5}$, muchas de los cuales reproducen el ritual del baño o la sesión de tocador de las mujeres de buena posición.

Es cierto que la ilustración comercial supo reflejar como nadie la moda y las costumbres de las primeras décadas del siglo XX, pero también es verdad que los anuncios ilustrados poseen un valor educativo capaz de influir en la sociedad; por ejemplo, los hábitos higiénicos que los jabones Heno de Pravia, La Toja o Flores del Campo transmiten a sectores de la sociedad antes ajenos a la higiene femenina e infantil.

El siguiente dibujo (figura 5) de Federico Ribas de 1925 para Heno de Pravia representa a una madre en actitud de instruir a su hijo en la costumbre de lavarse con jabón, mostrándole la pastilla de Heno de Pravia. La escena expresa la idea de "educar para vender" (Alvarado, 2005), que es lo que viene a decir el texto en unas cuantas líneas. El anuncio es un precedente de lo que sería, un lustro después, la campaña educativa para la higiene bucal que dirigió Prat Gaballí para el dentífrico Dens de Gal. 


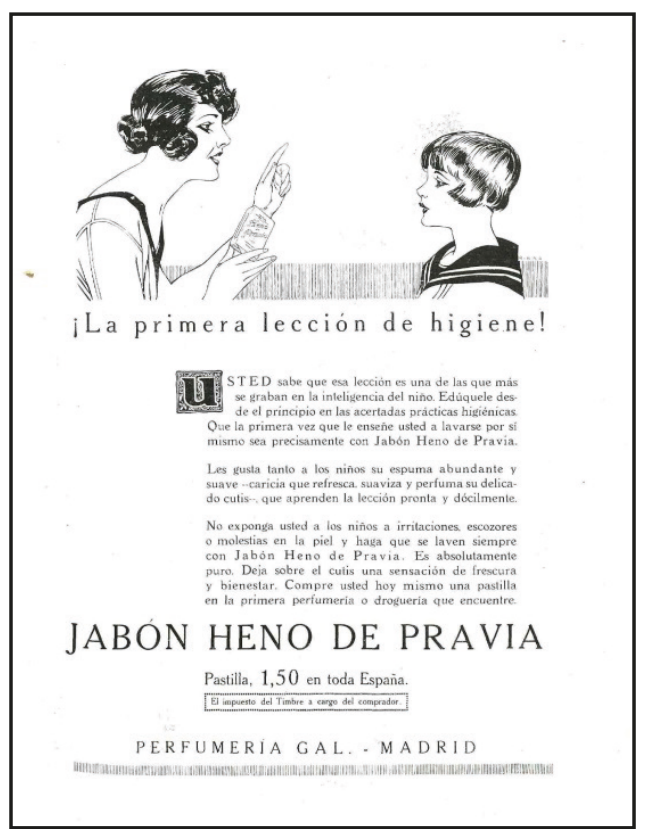

Figura 5: La Esfera, 11/04/1925

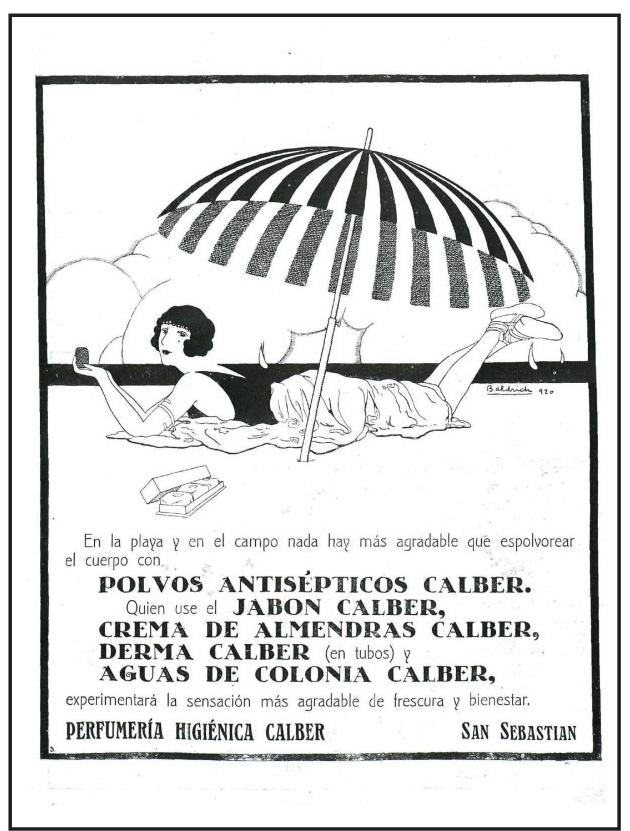

Figura 6: La Esfera, 4/09/1920

Por otra parte, en los años veinte se estableció la costumbre de salir al campo o a la playa durante las vacaciones. Aunque desde principios de siglo la buena sociedad acudía a tomar los baños al Cantábrico por aquello de que era bueno para la salud, aún no se relacionaba la playa con tomar el sol, hacer deporte o pasarlo bien. En este sentido, el dibujo (figura 6) de 1920 del catalán Roberto Martínez Baldrich (18951959) para Calber, que muestra a una joven tumbada en la arena de la playa bajo una sombrilla, adelanta la idea de disfrute que será habitual en la década de los sesenta. El texto -debajo en un faldón- que acompaña al dibujo asocia los productos higiénicos Calber con la sensación agradable, refrescante, de bienestar del mar, valores que van más allá de lo saludable.

A las actividades al aire libre siguió el deporte, una práctica que acababa de llegar a España y que sería fomentada en las ilustraciones comerciales, relacionándolas con productos de perfumería. Claro ejemplo de ello es el dibujo (figura 7) que Federico Ribas hizo en 1929 para el Agua de Colonia Añeja de Gal. La imagen representa a una mujer dispuesta para esquiar, equipada al estilo de entonces. En esta ocasión, el texto, de dimensiones similares a la ilustración e integrado en el dibujo, resalta las cualidades tonificantes de un producto que no debe faltar en el equipo del excursionista. 


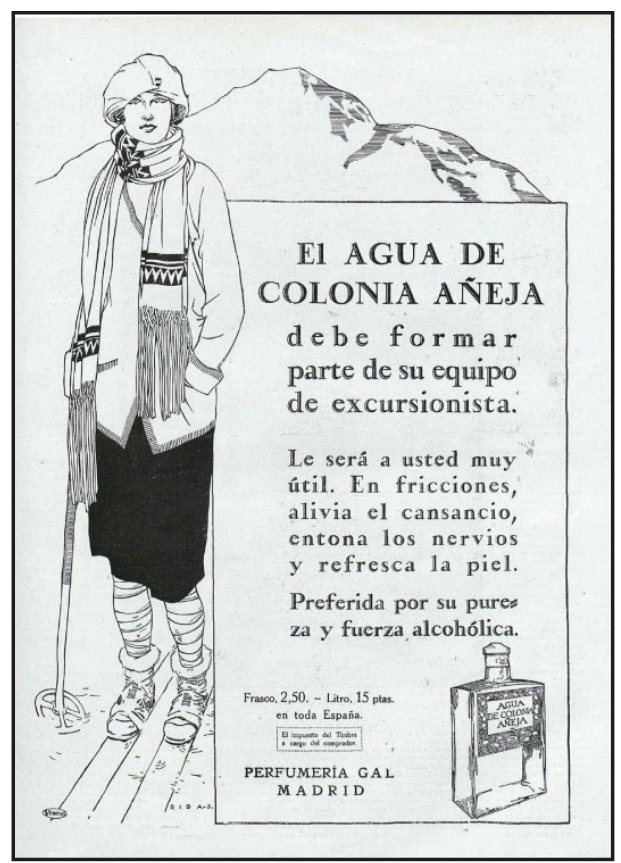

Figura 7: La Esfera, 2/02/1929

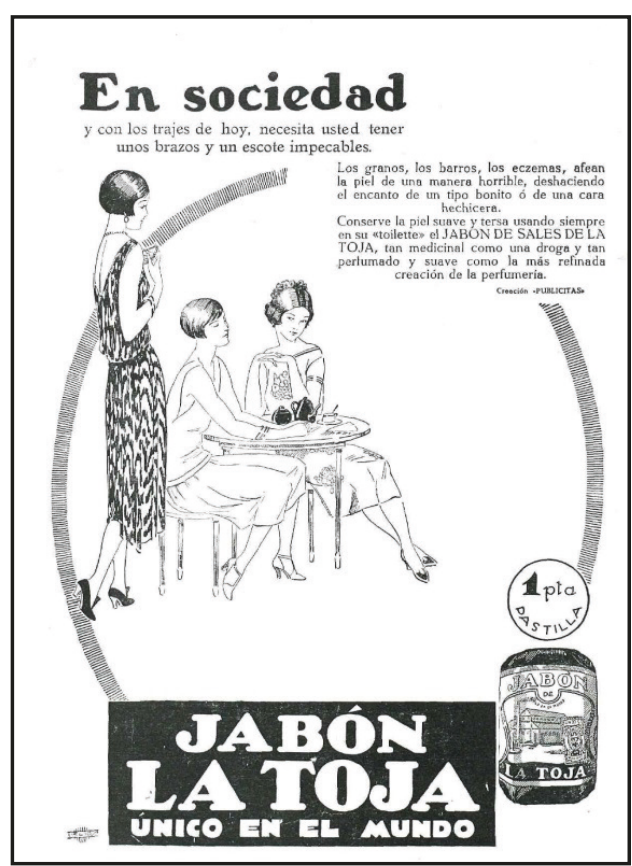

Figura 8: La Esfera, 16/10/1926

Con la nueva moda se modificaron costumbres en la vida cotidiana de las mujeres, por ejemplo, en lo que hace al arreglo personal. Como los vestidos se aligeraron, quedando parte del cuerpo al descubierto, surgió la necesidad de dedicarle tiempo y cuidados hasta entonces innecesarios. Las marcas de perfumería supieron aprovechar la ocasión y crearon nuevos productos o asociaron los ya existentes a los valores emergentes. Un ejemplo es la ilustración (figura 8), anónima, de 1926 del jabón de La Toja. El dibujo presenta a tres señoritas tomando el té que lucen vestidos vaporosos, sin mangas y escotados. El texto, integrado en el dibujo, esgrime como argumento de venta las propiedades curativas del producto, que garantiza la belleza a una piel expuesta continuamente a todas las miradas.

\section{Conclusiones}

En los años veinte la ilustración publicitaria atraviesa uno de sus mejores periodos debido a una pléyade de grandes dibujantes: Penagos, Ribas, Loygorri, Baldrich o Varela de Seijas, entre otros -representantes del Art Déco-, que colaboraron asiduamente en La Esfera y otras revistas gráficas. La mayoría disfrutaron de estancias en París y Londres donde tuvieron la oportunidad de conocer las vanguardias artísticas y la alta costura parisina, así como la ocasión de vivir los cambios sociales que se sucedían de forma vertiginosa en las principales capitales europeas. Aunque Penagos 
creó un prototipo femenino propio, y en menor medida también Ribas, ciertamente que estos viajes les abrieron nuevos horizontes.

Pues bien, con sus dibujos para marcas de automóviles, cosméticos o tabaco contribuyeron a difundir la moda, promover el deporte, introducir el hábito de fumar en la vida cotidiana de las mujeres de la alta burguesía o modificar costumbres higiénicas entre la población infantil.

Los anuncios para coches de lujo de Penagos y Ribas acercaron la moda parisina a las españolas de buena posición, pero también despertaron el deseo y la ilusión en las mujeres de la pequeña y mediana burguesía. Lo mismo se puede decir de las ilustraciones de Varela de Seijas para una marca de cigarrillos, que asocian el estilo chic y desenfadado de la protagonista del dibujo con la modernidad que significa fumar para la población femenina.

Igualmente, las ilustraciones para las casas de perfumería de Ribas y Baldrich reproducen la vestimenta y el peinado de los años veinte e introducen nuevos hábitos: como la práctica del deporte, disfrutar de la playa o de una salida a la montaña, y de paso sugieren el consumo de un nuevo producto para el cuidado de una piel, ahora, debido a las imposiciones de la moda, expuesta al sol y a todas las miradas.

Por otra parte, no cabe duda de que la belleza de estas ilustraciones comerciales, "anuncios de autor", constituyen una renovación del anuncio y una aportación a la Historia del Arte.

Con este artículo se ha pretendido mostrar el influjo de la publicidad en el arte, algo menos conocido que el influjo del arte en la publicidad; no olvidemos que los autores de estas ilustraciones tuvieron una dedicación plena a la actividad publicitaria, la cual constituyó su principal medio de vida. En segundo lugar, desarrollaron una idea gráfica respetando siempre el concepto publicitario del anuncio; de aquí que los productos fueran un éxito de ventas.

Por último, los dibujantes de esta generación imprimieron un sello propio a la publicidad española de la época y renovaron el diseño gráfico y la ilustración publicitaria. Hoy su obra comercial es de plena actualidad y adquiere el mismo rango que el resto de su producción artística: se continúan organizando exposiciones y son objetivo de los coleccionistas.

\section{Referencias bibliográficas}

ALVARADO, M. A. y DE ANDRÉS, S. (1998). "Gal: Un siglo de perfumería, un siglo de publicidad”. En: Publifilia, Revista de culturas publicitarias, $\mathrm{n}^{\circ} 1$. Segovia: Colegio Universitario de Segovia. P. 23-49

ALVARADO, M.A. (2005). "Educar para vender: un caso emblemático de publicidad educativa y comercial en la España de 1930”. En BERMEJO, J. (coord.). Publicidad y cambio social. Sevilla: Comunicación Social. P. 63-99. 
ALTABELlA, J. (1950): "Emiliano Ramírez Ángel al servicio de la publicidad". En: Arte Comercial. Revista técnica de publicidad y organización, $\mathrm{n}^{\circ} 22$, año IV. Madrid. P.9.

Arte Comercial (1950). "Apuntes sobre la publicidad y la perfumería en España". En: Arte Comercial, Revista técnica de publicidad y organización, $\mathrm{n}^{\circ} 22$, año IV. Madrid. P. 24-27.

ARRIBAS MACHO, J.M. (1994). "Antecedentes de la sociedad de consumo en España: de la Dictadura de Primo de Rivera a la II República”. En: Política y Sociedad, 16. Madrid: Universidad Complutense. P. 149-168. Recuperado 11/10/2014. http://www.revistas.ucm.es/index.php/POSO/article/download/.../30294

DE ANDRÉS, S. y ALVARADO, M.A. (1999). "Gal: un siglo de perfumería, un siglo de publicidad". En: Publifilia, Revista de culturas publicitarias, $\mathrm{n}^{\circ} 2$. Segovia: Colegio Universitario de Segovia. P. 49-64.

DE VICENTE DOMÍNGUEZ, A. (2011). "Arte y Publicidad: Producción científica en universidades españolas (1998-2010)". En: Revista Mediterránea de Comunicación, vol.2, $\mathrm{n}^{\circ}$. 1. Alicante: Universidad de Alicante. P. 209-220. Recuperado 27/11/2014. DOI: http://dx.doi.org/10.14198/MEDCOM2011.2.11

DESVOIS, J.M. (1977). La prensa en España (1900-1931). Madrid: Siglo Veintiuno de España.

EGUIZÁBAL, R. (2014). El cartel en España. Madrid: Cátedra. (2002). "El arte al servicio de la técnica". En: Publifilia. Revista de culturas publicitarias, $\mathrm{n}^{\mathrm{o}}$ 6. Segovia: Colegio Universitario de Segovia. P.65-68

(1998). Historia de la Publicidad. Madrid: Eresma\&Celeste.

FOLGUERA, P. (1987). Vida cotidiana en Madrid. Primer tercio del siglo a través de las fuentes orales. Madrid: Comunidad de Madrid. Recuperado 10/9/2014. http://www.madrid.org/edupubli/cgi.../WPUB_BD.exe?...)

GARCÍA DELGADO, J.L. (2002). La modernización económica en la España de Alfonso XIII. Discurso de recepción en la Real Academia de Ciencias Morales y Políticas. Madrid. Recuperado 5/8/2014. http://www.racmyp.es/docs/discursos/ D25.pdf

GARCÍA RUESCAS, F. (2000). Historia de la Publicidad y del Arte Comercial en España. Desde tiempos remotos hasta el final del siglo XX. Madrid :Arus.

GÓMEZ APARICIO, P. (1974). Historia del periodismo español. De las guerras coloniales a la Dictadura. Madrid: Editora Nacional.

LOZANO BARTOLOZZI, M. (1992). "Los carteles y el arte publicitario de Salvador Bartolozzi (1882-1950)". En: Norba: Revista de arte, $\mathrm{n}^{\circ} 12$. Badajoz: Universidad de Extremadura. P.187-202. Recuperado 21/12/2014. http://dialnet.unirioja.es/ servlet/oaiart?codigo $=107454$

MARTÍN, I. (2002). "Consumo y publicidad en la España del primer tercio del siglo XX”. En: Publifilia, Revista de culturas publicitarias, $\mathrm{n}^{\circ}$ 6. Segovia: Colegio Universitario de Segovia. P.37-48

ORTIZ GAITÁN, J. (2003). Imágenes del deseo: arte y publicidad en la prensa ilustrada mexicana (1894-1939). México: Universidad Nacional Autónoma de México. 
QUINTAS FROUFE, E. (2008). "Origen y proliferación de los concursos de carteles a principios del siglo XX: el concurso de la perfumería Gal (1916)". En: Área Abierta, $n^{\circ}$ 21. Madrid: Universidad Complutense. P.1-13. Recuperado 4/7/2014. http://www.revistas.ucm.es/index.php/ARAB/article/viewFile/.../4133.

QUINTAS FROUFE, E. (2012). "La evolución de la comunicación publicitaria: Análisis de la obra de Federico Ribas para Perfumería Gal (1916-1936)". En: Revista Latina de Comunicación Social, 67. La Laguna (Tenerife): Universidad de La Laguna, páginas 439 a 469. Recuperado 2 /5/ 2013. http://www.revistalatinacs.org/067/art/963_Columbia/19_eva.html. DOI: 10.4185/RLCS-2012-963

PÉREZ ROJAS, J. (1990). Art déco en España. Madrid: Cátedra.

PÉREZ RUIZ, M.A. (2001). La publicidad en España. Anunciantes, agencias y medios 1850-1950. Madrid: Fragua.

PRAT GABALLÍ, P. (1934). Publicidad racional. Barcelona:Labor.

RAMOS PÉREZ, R. (2011). "El arte de la belleza. Colección de la Biblioteca Nacional de España". El arte de la belleza. Exposición organizada por la Biblioteca Nacional de España del 15 de marzo al 5 de junio. Madrid: Ministerio de Cultura. P.37-49. Recuperado 10/09/2014. www.bne.es/es/.../Guias/ArteDeLaBelleza/.../ ElArteDeLaBelleza.pdf

SÁNCHEZ VIGIL, J.M. (2001). La documentación fotográfica en España: revista La Esfera (1914-1920). Tesis doctoral. Madrid: Universidad Complutense.

SEOANE, M. \& SÁIZ, M.D. (1998). Historia del periodismo en España. 3. El siglo XX: 1898-1936. Madrid: Alianza.

VALBUENA ÁlVAREZ, R. Y SALVADOR BENÍTEZ, A. (2014). "Actividad publicitaria en la revista La Esfera (1914-1931). Un estudio por sectores". En: Documentación de las Ciencias de la Información, vol.37. Madrid: Universidad Complutense. P.59-89. Recuperado 29/11/2014. http://dx.doi.org/10.5209/rev_ DCIN.2014.v37.46820

\section{Notas}

1 El consumo es una muestra de los valores predominantes en una sociedad en un momento determinado (Arribas Macho, 1994: 149).

2 Una materia en alza en la producción científica universitaria. Si bien las investigaciones se han centrado más en estudiar la influencia del arte en la publicidad que del influjo de la publicidad en el arte. (De Vicente Domínguez, 2011).

3 Para hacerse una idea, entre 1914 y 1931 La Esfera publicó 20.300 anuncios siendo el sector editorial el de mayor presencia, seguido por la salud, la perfumería y la cosmética y ya más alejados la fotografía, alimentación y textil (Valbuena Álvarez y Salvador Benítez, 2014:67).

4 Por ejemplo, el número Extraordinario de 6 de junio de 1929 consta de 248 páginas.

5 Eguizábal (2002:66) calcula, partiendo de datos proporcionados por Prat Gaballí, que Federico Ribas produjo en ocho años unos 6.400 dibujos para Gal. 